Check for updates

Cite this: Phys. Chem. Chem. Phys., 2019, 21, 1277

Received 14th November 2018 Accepted 14th December 2018 DOI: $10.1039 / c 8 c p 07053 a$

rsc.li/pccp

\title{
Incremental NH stretching downshift through stepwise nitrogen complexation of pyrrole: a combined jet expansion and matrix isolation study $\dagger$
}

\author{
Sönke Oswald, (D) a Martin A. Suhm (D) *a and Stéphane Coussan (D)*b
}

\begin{abstract}
Aggregates of pyrrole with nitrogen are studied by Fourier transform infrared spectroscopy in supersonic jet expansions as well as in neon, argon and nitrogen cryomatrices. The $\mathrm{NH}$ stretching vibration undergoes a significant downshift upon switching from isolated gas phase conditions to bulk nitrogen matrices, which can be reconstructed incrementally by stepwise cluster formation with an increasing number of nitrogen molecules both in supersonic expansions and neon or argon matrices. The modelling of the bulk matrix shift by finite cluster theory remains an interesting challenge. Self-aggregation of pyrrole also yields the first spectra of the homodimer and -trimer in a neon matrix, showing particularly small (up to $10 \mathrm{~cm}^{-1}$ ) deviations from the isolated gas phase values.
\end{abstract}

\section{Introduction}

Isolation of transient species or weakly bound molecular aggregates in cryogenic matrices provides one of the most powerful and sensitive methods for subsequent spectroscopic studies of their structure and dynamics. ${ }^{1}$ However, spectral shifts and splittings from unperturbed gas phase values due to the bulk environment are frequently observed even for light, soft and less perturbative matrix hosts such as parahydrogen ${ }^{2}$ or neon. $^{3}$ The significant electric quadrupole moment of molecular nitrogen ${ }^{4}$ results in a comparatively strong perturbation found in corresponding matrices. ${ }^{5}$ Partial positive charges at the centre and negative charges at the molecule ends ${ }^{6}$ lead to a more specific and directional guest-host interaction than for the similarly large argon host. ${ }^{7}$ Stepwise nanocoating of hydrogenbonded organic compounds with matrix host molecules in supersonic expansions is a useful tool in understanding gas-to-matrix shifts $^{8-10}$ and may enable a more rigorous comparison of matrix isolation spectra to theoretical predictions.

In any molecular nitrogen solvation environment, the simple aromatic pyrrole $\left(\mathrm{C}_{4} \mathrm{H}_{4} \mathrm{NH}\right)$ ring offers the possibility of competition between more directional $\mathrm{NH} \cdots \mathrm{N}_{2}$ hydrogen bonds and less directional aromatic $\pi \cdots \mathrm{N}_{2}$ interactions. ${ }^{11}$ The $\mathrm{NH}$ stretching

\footnotetext{
${ }^{a}$ Institut für Physikalische Chemie, Universität Göttingen, Tammannstr. 6, 37077 Göttingen, Germany. E-mail: msuhm@gwdg.de

${ }^{b}$ CNRS, PIIM, Laboratoire des Interactions Ioniques et Moléculaires, Aix Marseille Universite, 13397 Marseille Cedex 20, France. E-mail: stephane.coussan@univ-amu.fr $\dagger$ Electronic supplementary information (ESI) available: Keywords for calculations, higher energy conformers, detailed theoretical predictions, coordinates of molecular structures. See DOI: 10.1039/c8cp07053a
}

vibration provides a sensitive indicator for complex formation even with the weakly interacting nitrogen binding partner. Observable effects such as spectroscopic shifts and infrared intensity enhancements are much less pronounced in most other fundamental modes of the symmetric pyrrole molecule and therefore more difficult to judge experimentally. Observation of a possible infrared activation of the NN stretching vibration through complexation ${ }^{12-14}$ is hindered by spectral overlap with the antisymmetric stretching vibration of atmospheric carbon dioxide.

Homoaggregates of pyrrole and their respective spectral fingerprints have been studied with a variety of different experimental techniques such as optothermal molecular beam, ${ }^{15}$ microwave, ${ }^{16,17}$ cavity ring-down, ${ }^{18}$ infrared photodissociation ${ }^{19}$ and aromatically labelled UV/IR double resonance ${ }^{20}$ spectroscopy as well as size selection by scattering. ${ }^{21}$ Broadband infrared spectroscopy in para-hydrogen, ${ }^{22}$ nitrogen ${ }^{22,23}$ and argon matrices, ${ }^{7}$ solution ${ }^{24,25}$ and supersonic expansions ${ }^{26,27}$ as well as most other vibrational spectroscopy focus primarily on the $\mathrm{NH}$ stretching region. Corresponding infrared spectra in neon matrices provided in this work facilitate previously uncertain trimer band assignments in argon matrix. ${ }^{7}$

More importantly, NH stretching gas-to-matrix shifts are rationalised and incrementally reproduced by stepwise nitrogen complexation in neon and argon matrices as well as supersonic expansions. All spectra as well as harmonic density functional theory predictions show a weak, but distinct downshift of the $\mathrm{NH}$ stretching vibration upon hydrogen bond formation, clearly correcting a proposed unusual upshift based on anharmonic calculations and nitrogen matrix spectra ${ }^{23}$ which has received 
considerable attention ${ }^{22,28-30}$ despite being challenged by more reliable calculations. ${ }^{19}$

\section{Experimental methods}

For matrix isolation experiments, ${ }^{31-34}$ pyrrole (Aldrich, >98\%) was subjected to multiple freeze-pump-thaw cycles under primary vacuum to remove dissolved gases. Pyrrole was then mixed with matrix gases, neon (Air Liquide, N50 grade), argon and nitrogen (Air Liquide, N60 grade), in partial ratii $\mathrm{Py} / \mathrm{N}_{2} / \mathrm{MG}$ (Py, pyrrole, MG, matrix gas) ranging from $0.25 / 0 / 1000$ to $0.28 / 55 / 1000$. Mixtures were deposited onto a gold-plated copper cube cooled to $4.7 \mathrm{~K}$ in neon and $20 \mathrm{~K}$ in argon and nitrogen by a closed-cycle cryogenerator (Cryomech, PT-405). Cryostat and sample-carrier were protected from thermal background radiation by a chrome-plated brass shield kept at $\approx 32 \mathrm{~K}$. Controlled heating (Lakeshore, Model 336) of the sample carrier was carried out with a $50 \Omega$ resistor, while the background pressure in the vacuum chamber was kept at $10^{-7}$ mbar by a turbomolecular pump. Fourier transform IR (FTIR) spectra were all recorded at $4.7 \mathrm{~K}$ in the reflection mode using a Bruker IFS 66/S spectrometer (resolution: $0.12 \mathrm{~cm}^{-1}$ ) equipped with a MCT detector.

For measurements in pulsed supersonic expansions, ${ }^{35}$ helium (Linde, 99.996\%) optionally mixed with nitrogen (Air Liquide, 99.996\%) was guided through a thermostatted glass saturator containing liquid pyrrole (abcr, 99.8\%), resulting in molar fractions of about $0.1 \%$ pyrrole in the gas mixture, depending on the vapour pressure controlled by the $-20{ }^{\circ} \mathrm{C}$ saturator temperature. Hence, mixtures with partial ratii Py/ $/ \mathrm{N}_{2} / \mathrm{He}$ ranging from $1 / 25 / 1000$ to $1 / 150 / 1000$ were employed for the expansions. From a $67 \mathrm{~L}$ Teflon coated reservoir at a stagnation pressure of 0.75 bar the gas escaped through six solenoid valves into a preexpansion chamber connected with the vacuum chamber through a $(600 \times 0.2) \mathrm{mm}^{2}$ slit nozzle. A Bruker IFS $66 \mathrm{v} / \mathrm{S}$ FTIR spectrometer equipped with a $150 \mathrm{~W}$ tungsten lamp, $\mathrm{CaF}_{2}$ optics and a liquid nitrogen cooled $3 \mathrm{~mm}^{2}$ InSb detector recorded synchronized broadband FTIR spectra of the resulting supersonic jet expansion at a resolution of $2 \mathrm{~cm}^{-1}$ (as a compromise between spectral resolution power and signal-to-noise ratio) with the infrared beam crossing perpendicularly to the gas flow propagation direction. Maintenance of sufficiently low background pressures during $147 \mathrm{~ms}$ gas pulses was ensured by an attached $23 \mathrm{~m}^{3}$ buffer volume, continuously evacuated by a series of roots pumps at a speed of $2500 \mathrm{~m}^{3} \mathrm{~h}^{-1}$ and a $25 \mathrm{~s}$ delay between subsequent pulses. A more detailed description of the setup ( filet-jet) can be found in ref. 35 .

\section{Quantum chemical calculations and nomenclature}

The studied molecules are abbreviated as $\mathrm{P}$ (pyrrole) and $\mathrm{N}$ (nitrogen). For the description of hydrogen bonded cluster compositions, these single letters are repeated in donor-acceptor sequence. The docking site of nitrogen at the pyrrole monomer is marked by a subscript to the $\mathrm{N}$, discriminating between the $\mathrm{NH}$ proton $(\mathrm{H})$, the aromatic $\pi$ electron system $(\pi)$ or the $\mathrm{CH}$ backbone (C). Structure optimisations and harmonic frequency calculations were performed at the B3LYP-D3(BJ)/aVTZ level of computation with the Gaussian $09^{36}$ (Rev. E01) program package. For selected clusters, these were complemented by additional anharmonic frequency calculations ${ }^{37}$ (second order vibrational perturbation theory, VPT2) and $\operatorname{CCSD}(\mathrm{T}) / \mathrm{aVTZ}$ single point energies. A full list of all employed keywords can be found in Table S1 in the ESI. $\dagger$ No scaling of calculated harmonic wavenumbers is applied, because the focus is on very small shifts due to matrix interaction which are neither changed significantly by scaling factors nor expected to change much upon proper inclusion of anharmonicity (currently not possible for such weakly interacting, somewhat large molecular complexes).

Structures of P homoclusters (Fig. 1) were reoptimised from known literature models. ${ }^{27}$ The PP dimer forms a $\mathrm{NH} \cdots \pi$ hydrogen bond in a T-shape with the two molecule planes tilted from a perpendicular arrangement to about $55^{\circ},{ }^{17}$ similar to pyrrole coordination of other aromatic acceptors. ${ }^{38}$ The cyclic hydrogen bond topology in the PPP trimer allowing for substantial cooperativity which more than triples the dissociation energy has been experimentally demonstrated by complementary infrared and Raman NH stretching spectra. ${ }^{18,27}$

In comparison to $\mathrm{P}$ homoclusters, nitrogen solvation complexes are energetically substantially less favoured with predicted dissociation energies of about $6 \mathrm{~kJ} \mathrm{~mol}^{-1}$ for the most stable heterodimers, reasonably close to the experimental value of $(6.67 \pm 0.08) \mathrm{kJ} \mathrm{mol}^{-1}$ found for the mixed dimer of 1-naphthol and nitrogen. ${ }^{39}$ For the first attached $\mathrm{N}_{2}$ molecule with its quadrupole moment comprised of positive partial charge in the molecule centre and negative partial charge at its ends, $\mathrm{P}$ offers two almost equally attractive binding sites. The $\mathrm{NH}$ proton and the $\pi$-electron density above the aromatic ring plane (Fig. 2) compete for the solvent with the first motif winning for positively charged $\mathrm{P}^{19}$ and the latter being favoured in the most stable binary aggregate of neutral $\mathrm{P}$ and argon $^{40}$ Only the hydrogen bonded $\mathrm{N}_{\mathrm{H}}$ complex structure is predicted with a small NH stretching downshift in the double harmonic approximation (Table 1), while $\pi$ binding is spectrally unimpressive. Both the $\pi$-system and the NH proton offer enough space for secondary $\mathrm{N}_{2}$ attachment and those binding sites are subsequently filled upon increasing complexation. Interactions between attached $\mathrm{N}_{2}$

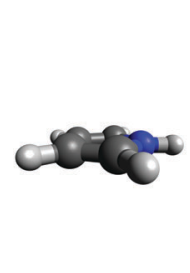

$P$

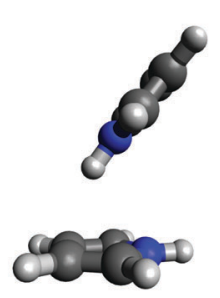

PP (23.7)

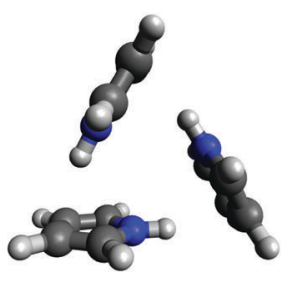

PPP (80.6)
Fig. 1 Stable structures of the pyrrole monomer (P), dimer (PP) and trimer (PPP) optimised at the B3LYP-D3(BJ)/aVTZ level. Harmonically zero-point corrected dissociation energies in $\mathrm{kJ} \mathrm{mol}^{-1}$ are provided in parentheses. 


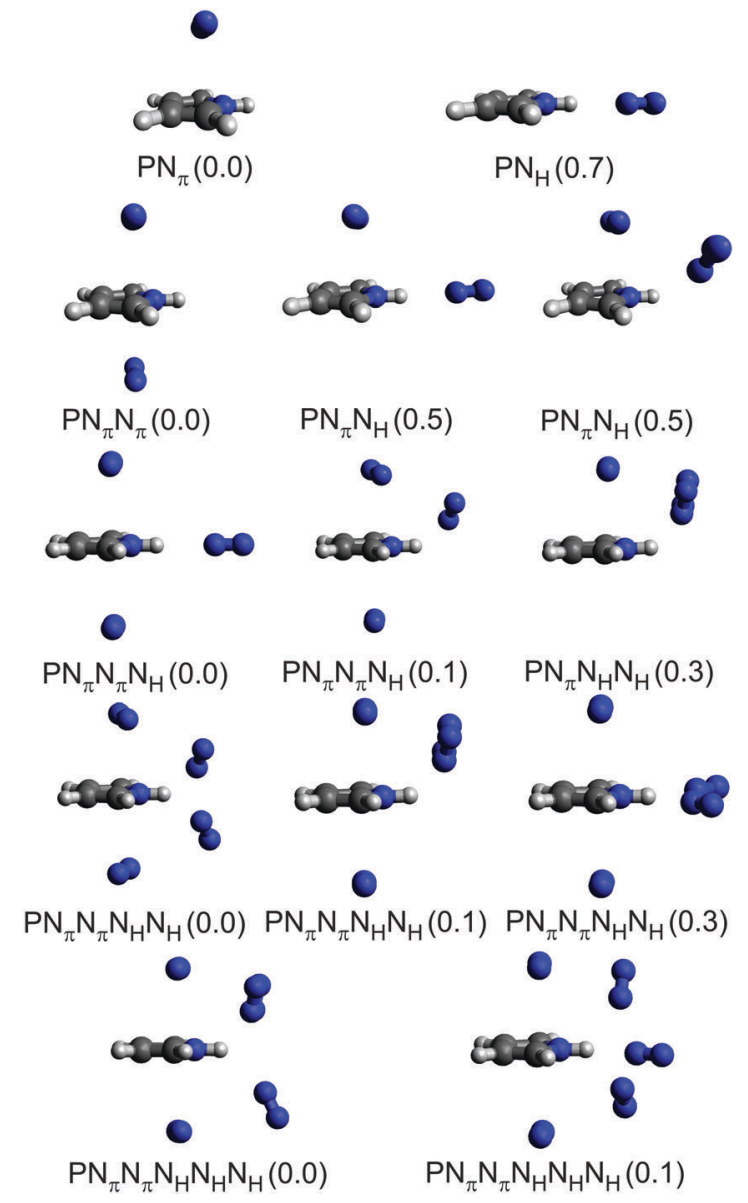

Fig. 2 Most stable structures found for heteroaggregates of the pyrrole monomer $(P)$ with increasing $N_{2}$ coordination optimised at the B3LYP$\mathrm{D} 3(\mathrm{BJ}) / \mathrm{aVTZ}$ level. Relative energies in $\mathrm{kJ} \mathrm{mol}^{-1}$ calculated from CCSD(T)/ aVTZ single-point calculations and harmonic zero-point vibrational energy from B3LYP-D3(BJ)/aVTZ are given in parentheses (bottom row exclusively B3LYP-D3(BJ)/aVTZ energies).

molecules open up slightly different structural motifs in larger clusters, but the generally preferred binding sites at $\mathrm{P}$ remain the same. Up to the mixed tetramer with three $\mathrm{N}_{2}$ molecules bound at $\mathrm{P}$, increasing spectral $\mathrm{NH}$ stretching downshifts of $\mathrm{N}_{\mathrm{H}}$ conformers are predicted harmonically as expected for cooperative solvation. However, for larger aggregates such as pentamers and hexamers the prediction for the most stable solvation complexes switches to small upshifts hinting at substantial difficulties of the employed theoretical method in accurately modelling $\mathrm{N}_{2}$ embedding which will be demonstrated below. Additional conformers which are more than $1.0 \mathrm{~kJ} \mathrm{~mol}^{-1}$ less stable than the respective minimum energy structures can be found in Fig. S1-S5 and the respective spectroscopic predictions are summarised in Table S2 in the ESI. $\dagger$ In the absence of detailed interconversion barrier analyses, it remains unclear which of the higher energy structures may contribute to the kinetically controlled jet experiments. For all cluster sizes, there are significantly $\left(>5 \mathrm{~cm}^{-1}\right)$ downshifting structure representatives (typically involving $\mathrm{N}_{\mathrm{H}}$ coordination), but they tend to move higher in relative energy with increasing coordination number. One evident trend in these computed data independent on complex binding energy is that directed $\mathrm{NH} \cdots \mathrm{N}_{2}$ contacts often lead to downshifts of the $\mathrm{NH}$ stretching frequency, whereas structures with $\mathrm{NH}$ pointing between two $\mathrm{N}_{2}$ units tend to show slight upshifts.

Anharmonic predictions for low frequency large amplitude motions are unphysical in all tested cases except the rigid $\mathrm{P}$ monomer, indicating limitations of the VPT2 approach when treating soft, nonrigid molecular systems such as nitrogen aggregates. ${ }^{10}$ While localised high frequency modes such as NH stretching vibrations are typically less affected, errors are still introduced via coupling to the low frequency vibrations and could be of similar magnitude as the entire hydrogen bond induced shift.

\section{Results and discussion}

\subsection{Neon, argon and nitrogen matrices}

To reduce competition between the formation of energetically favoured P homoclusters and nitrogen complexation, $\mathrm{P}$ is highly diluted to concentrations as low as $0.025 \%$ for all matrices, minimising homoaggregation. NH stretching FTIR spectra of $\mathrm{P}$ in a neon (Fig. 3) matrix show a broad and structured monomer band, ranging from 3540 to $3525 \mathrm{~cm}^{-1}$. This provides strong evidence for the sensitivity of the $\mathrm{NH}$ stretching mode to different lattice environments even for the partially quantum-delocalized and soft neon matrix and underscores the suitability of pyrrole for such a kind of study. After annealing to $9 \mathrm{~K}$ cluster formation is increased and the PP donor vibration at $3433.8 \mathrm{~cm}^{-1}$ gains intensity as well as the PPP band at $3386.0 \mathrm{~cm}^{-1}$. In the argon matrix $^{7}$ (Fig. 4) site splitting between 3523.1, 3519.9 and the dominant site at $3521.1 \mathrm{~cm}^{-1}$ is observed for P. After annealing to $30 \mathrm{~K}$ the PP donor vibrations at $3420.2,3417.6$ and $3414.6 \mathrm{~cm}^{-1}$ gain intensity and various PP acceptor and PPP vibrations emerge at 3517.9, 3514.1, 3511.5, 3509.1 and $3378.6 \mathrm{~cm}^{-1}$. The vibrational signal at $3378.6 \mathrm{~cm}^{-1}$ was also observed in the previous work by Fausto and co-workers ${ }^{7}$ and very tentatively assigned to the tetramer. The gas phase shift trend ${ }^{27}$ (Table 2) already makes an assignment to the trimer more likely, which is further corroborated by the new neon matrix value. It is not unexpected that the neon matrix shows the smallest deviations from the jet spectral positions.

In a nitrogen matrix (Fig. 5), the monomer band also displays substantial site splitting with peaks at 3519.5, 3514.2, $3512.7,3511.2$ and $3509.1 \mathrm{~cm}^{-1}$. After annealing to $30 \mathrm{~K}$, unstable sites are depopulated in favour of mainly that at $3514.2 \mathrm{~cm}^{-1}$. Only small fractions of the sites at 3509.1 and $3519.5 \mathrm{~cm}^{-1}$ remain with the latter being falsely assumed as a sign of an upshifted $\mathrm{NH}$ stretching band position due to $\mathrm{NH} \cdots \mathrm{N}_{2}$ hydrogen bonding in the binary aggregate of $\mathrm{P}$ and nitrogen in ref. 23. The PP donor and PPP vibrations also grow in at $3423.8,3417.5,3415.1,3385.0$ and $3379.6 \mathrm{~cm}^{-1}$, alongside two acceptor vibrations at 3503.5 and $3501.1 \mathrm{~cm}^{-1}$.

The gas-to-matrix shift of the monomer increases from the weakly interacting neon over para-hydrogen and the more polarisable argon to quadrupolar nitrogen (Table 2). Similar behaviour 
Table 1 Theoretically predicted properties of the most stable $\mathrm{P}$ and $\mathrm{N}_{2}$ aggregates such as harmonic $\left(\omega_{\mathrm{NH}}\right)$ and anharmonic $\left(\tilde{\nu}_{\mathrm{NH}}\right) \mathrm{NH}$ stretching wavenumbers, lowest predicted harmonic $\left(\omega_{\llcorner}\right)$and anharmonic $\left(\tilde{\nu}_{L}\right)$ wavenumbers in $\mathrm{cm}^{-1}$, harmonic $\left(S_{\omega}\right)$ and anharmonic $\left(S_{\nu}\right)$ infrared band strengths in $\mathrm{km} \mathrm{mol}^{-1}$, spectroscopic shifts $\left(\Delta \omega_{\mathrm{NH}}, \Delta \tilde{\nu}_{\mathrm{NH}}\right)$ relative to $\mathrm{P}$ in $\mathrm{cm}^{-1}$ as well as relative electronic and harmonically zero-point corrected energies $\Delta E_{\mathrm{e}}$ and $\Delta E_{0}$ compared to the most stable cluster conformation in $\mathrm{kJ} \mathrm{mol}^{-1}$. All properties were calculated at the B3LYP-D3(BJ)/aVTZ level of approximation. Only the electronic energy was taken from CCSD(T)/aVTZ single-point calculations for all clusters except hexamers

\begin{tabular}{|c|c|c|c|c|c|c|c|c|c|c|}
\hline Structure & $\omega_{\mathrm{NH}}$ & $S_{\omega}$ & $\Delta \omega_{\mathrm{NH}}$ & $\omega_{\mathbf{L}}$ & $\tilde{\nu}_{\mathrm{NH}}$ & $S_{\nu}$ & $\Delta \tilde{\nu}_{\mathrm{NH}}$ & $\tilde{\nu}_{\mathrm{L}}$ & $\Delta E_{\mathrm{e}}$ & $\Delta E_{0}$ \\
\hline PP & $\begin{array}{l}3669 \\
3598\end{array}$ & $\begin{array}{l}72 \\
324\end{array}$ & $\begin{array}{l}-5 \\
-76\end{array}$ & 17 & - & - & - & - & - & - \\
\hline PPP & $\begin{array}{l}3553 \\
3553 \\
3536\end{array}$ & $\begin{array}{l}631 \\
631 \\
0\end{array}$ & $\begin{array}{l}-121 \\
-121 \\
-138\end{array}$ & 22 & - & - & - & - & - & - \\
\hline $\begin{array}{l}\mathrm{PN}_{\pi} \\
\mathrm{PN}_{\mathrm{H}}\end{array}$ & $\begin{array}{l}3674 \\
3669\end{array}$ & $\begin{array}{l}65 \\
206\end{array}$ & $\begin{array}{l}0 \\
-5\end{array}$ & $\begin{array}{l}21 \\
11\end{array}$ & $\begin{array}{l}3507 \\
3506\end{array}$ & $\begin{array}{l}51 \\
133\end{array}$ & $\begin{array}{l}-1 \\
-2\end{array}$ & $\begin{array}{l}(18810) \\
(20)\end{array}$ & $\begin{array}{l}0.0 \\
0.8\end{array}$ & $\begin{array}{l}0.0 \\
0.7\end{array}$ \\
\hline $\begin{array}{l}\mathrm{PN}_{\pi} \mathrm{N}_{\pi} \\
\mathrm{PN}_{\pi} \mathrm{N}_{\mathrm{H}} \\
\mathrm{PN}_{\pi} \mathrm{N}_{\mathrm{H}}\end{array}$ & $\begin{array}{l}3673 \\
3668 \\
3675\end{array}$ & $\begin{array}{l}65 \\
210 \\
94\end{array}$ & $\begin{array}{l}-1 \\
-6 \\
1\end{array}$ & $\begin{array}{l}18 \\
10 \\
8\end{array}$ & $\begin{array}{l}3517 \\
3505 \\
3508\end{array}$ & $\begin{array}{l}52 \\
131 \\
69\end{array}$ & $\begin{array}{l}9 \\
-3 \\
0\end{array}$ & $\begin{array}{l}(132) \\
(-22) \\
(23)\end{array}$ & $\begin{array}{l}0.0 \\
0.4 \\
0.7\end{array}$ & $\begin{array}{l}0.0 \\
0.5 \\
0.5\end{array}$ \\
\hline $\begin{array}{l}\mathrm{PN}_{\pi} \mathrm{N}_{\pi} \mathrm{N}_{\mathrm{H}} \mathrm{N}_{\mathrm{H}} \\
\mathrm{PN}_{\pi} \mathrm{N}_{\pi} \mathrm{N}_{\mathrm{H}} \mathrm{N}_{\mathrm{H}} \\
\mathrm{PN}_{\pi} \mathrm{N}_{\pi} \mathrm{N}_{\mathrm{H}} \mathrm{N}_{\mathrm{H}}\end{array}$ & $\begin{array}{l}3676 \\
3676 \\
3678\end{array}$ & $\begin{array}{l}122 \\
104 \\
168\end{array}$ & $\begin{array}{l}2 \\
2 \\
4\end{array}$ & $\begin{array}{l}10 \\
9 \\
4\end{array}$ & $\begin{array}{l}- \\
- \\
-\end{array}$ & $\begin{array}{l}- \\
- \\
-\end{array}$ & $\begin{array}{l}- \\
- \\
-\end{array}$ & $\begin{array}{l}- \\
- \\
-\end{array}$ & $\begin{array}{l}0.0 \\
0.0 \\
0.1\end{array}$ & $\begin{array}{l}0.0 \\
0.1 \\
0.3\end{array}$ \\
\hline $\begin{array}{l}\mathrm{PN}_{\pi} \mathrm{N}_{\pi} \mathrm{N}_{\mathrm{H}} \mathrm{N}_{\mathrm{H}} \mathrm{N}_{\mathrm{H}} \\
\mathrm{PN}_{\pi} \mathrm{N}_{\pi} \mathrm{N}_{\mathrm{H}} \mathrm{N}_{\mathrm{H}} \mathrm{N}_{\mathrm{H}}\end{array}$ & $\begin{array}{l}3674 \\
3674\end{array}$ & $\begin{array}{l}142 \\
174\end{array}$ & $\begin{array}{l}0 \\
0\end{array}$ & $\begin{array}{l}3 \\
8\end{array}$ & - & - & - & - & $\begin{array}{l}0.0 \\
0.1\end{array}$ & $\begin{array}{l}0.0 \\
0.1\end{array}$ \\
\hline
\end{tabular}

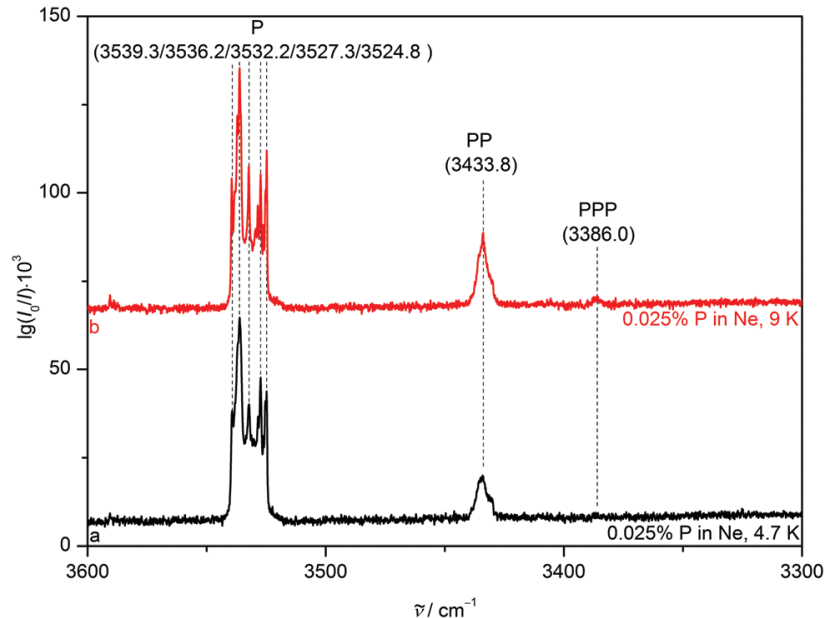

Fig. 3 NH stretching FTIR spectra of $0.025 \%$ pyrrole in a neon matrix after deposition at $4.7 \mathrm{~K}$ (trace a) and after annealing to $9 \mathrm{~K}$ and recooling to $4.7 \mathrm{~K}$ (trace b). Wavenumbers and assignments are provided.

with larger shifts due to cooperative effects ${ }^{9}$ is found for the dimer, although para-hydrogen-, nitrogen- and argon-induced shifts are rather similar. The cyclic trimer does not offer the acceptor $\mathrm{NH}$ as an attractive interaction site for the matrix host molecules, therefore the gas-to-matrix shifts are smaller and more uniform across the different matrix hosts than the ones observed for the dimer, closely mirroring effects found for small aliphatic alcohols. ${ }^{9}$ The consistently smaller matrix shift for the

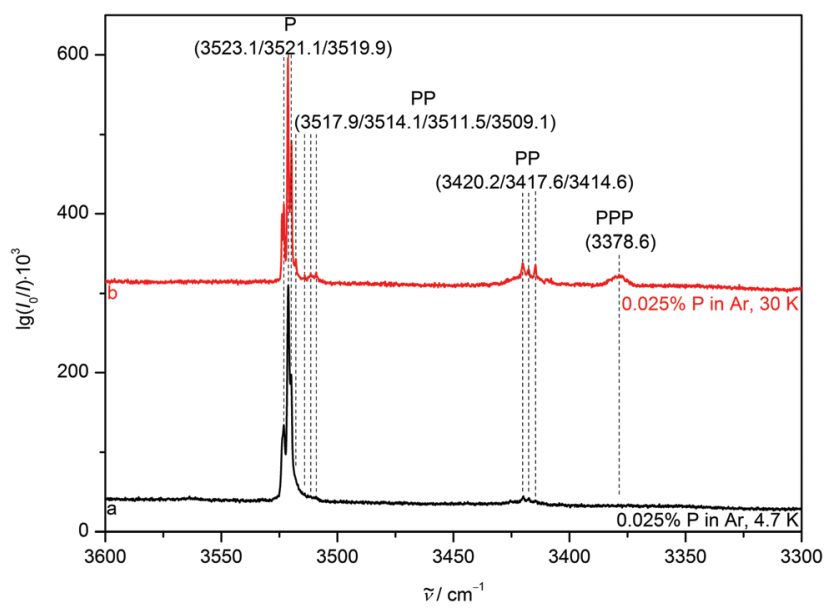

Fig. $4 \mathrm{NH}$ stretching FTIR spectra of $0.025 \%$ pyrrole in an argon matrix after deposition at $20 \mathrm{~K}$ and subsequent cooling to $4.7 \mathrm{~K}$ (trace a) as well as after annealing to $30 \mathrm{~K}$ and recooling to $4.7 \mathrm{~K}$ (trace b). Wavenumbers and (tentative) assignments are provided.

trimer is further proof of its cyclic nature, also in a strongly perturbing matrix environment.

\subsection{Nitrogen added to neon and argon matrices}

A noticeable average $\mathrm{NH}$ stretching downshift of roughly $18 \mathrm{~cm}^{-1}$ occurs for $\mathrm{P}$ when switching from neon to nitrogen hosts, most likely due to $\mathrm{NH} \cdots \mathrm{N}_{2}$ interactions. Stepwise addition of small nitrogen fractions such as 0.025 and $0.5 \%$ to neon 
Table $2 \mathrm{NH}$ stretching band centre positions $(\tilde{\nu})$ in $\mathrm{cm}^{-1}$ of the pyrrole monomer (P), dimer (PP) and trimer (PPP) measured in supersonic expansion and different cryomatrices as well as the gas-to-matrix wavenumber shift induced by matrix isolation $\left(\Delta \tilde{\nu}_{\mathrm{mi}}\right)$ in $\mathrm{cm}^{-1}$. Separate analysis for PP acceptor (upper row) and donor (lower row) vibrations is included

\begin{tabular}{|c|c|c|c|c|c|c|}
\hline Structure & \multicolumn{2}{|l|}{$\mathrm{P}$} & \multicolumn{2}{|l|}{$\underline{\mathrm{PP}}$} & \multicolumn{2}{|l|}{ PPP } \\
\hline Supersonic expansion $^{27}$ & 3531 & - & $\begin{array}{l}3524 \\
3444\end{array}$ & - & 3393 & - \\
\hline Neon & 3540,3525 & $9,-6$ & 3434 & -10 & 3386 & -7 \\
\hline para-Hydrogen ${ }^{22}$ & 3520 & -11 & $\begin{array}{l}3515,3512 \\
3424,3417\end{array}$ & $\begin{array}{l}-9,-12 \\
-20,-27\end{array}$ & 3385 & -8 \\
\hline Argon $^{7}$ & 3524,3520 & $-7,-11$ & 3418,3409 & $-26,-35$ & $\begin{array}{l}3396^{7} \\
{[3378]^{27}}\end{array}$ & $\begin{array}{l}3 \\
-15\end{array}$ \\
\hline Nitrogen ${ }^{22,23}$ & 3520,3509 & $-11,-22$ & $\begin{array}{l}3504,3501 \\
3424,3415\end{array}$ & $\begin{array}{l}-20,-23 \\
-20,-29\end{array}$ & 3385,3380 & $-8,-13$ \\
\hline
\end{tabular}

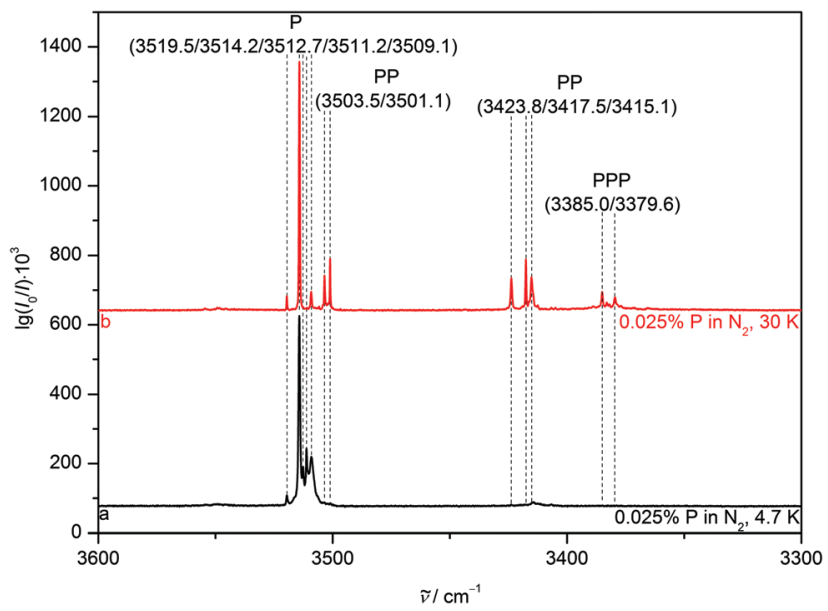

Fig. $5 \mathrm{NH}$ stretching FTIR spectra of $0.025 \%$ pyrrole in a nitrogen matrix after deposition at $20 \mathrm{~K}$ and subsequent cooling to $4.7 \mathrm{~K}$ (trace a) as well as after annealing to $30 \mathrm{~K}$ and recooling to $4.7 \mathrm{~K}$ (trace b). Wavenumbers and (tentative) assignments are provided.

matrices (Fig. 6, traces $\mathrm{b}$ to e) incrementally reproduces this shift. The $\mathrm{N}_{2}$ enriched neon matrices sustain annealing to $15 \mathrm{~K}$ for a few seconds and yield previously not observed downshifted bands at 3524.9, 3524.0, 3518.6, 3516.2 and $3514.7 \mathrm{~cm}^{-1}$, which are attributed to complexes of P and $\mathrm{N}_{2}$ in a neon environment, although assignment to certain calculated heteroaggregate structures (Fig. 2) is somewhat difficult in a bulk matrix. Annealing allows the different components to diffuse and create the molecular complexes, which most likely include a variety of $\mathrm{NH}$ and $\mathrm{N}_{\pi}$ aggregates as indicated by the broad range of observed downshifts. Addition of a larger nitrogen fraction of $5 \%$ (trace f) results in a broad NH stretching signal centred at $3520.2 \mathrm{~cm}^{-1}$, which is further downshifted to a position at $3515.5 \mathrm{~cm}^{-1}$ after annealing to $9 \mathrm{~K}$ (trace $\mathrm{g}$ ), in close proximity to the dominant pure nitrogen matrix band position (trace $\mathrm{h}$ ). We attribute the loss of structure upon increased $\mathrm{N}_{2}$ admixture to an incomplete and amorphous $\mathrm{N}_{2}$ embedding, i.e. interactions with $\mathrm{N}_{2}$ enriched neon matrix grains. This incomplete $\mathrm{N}_{2}$ embedding induces an inhomogeneous broadening due

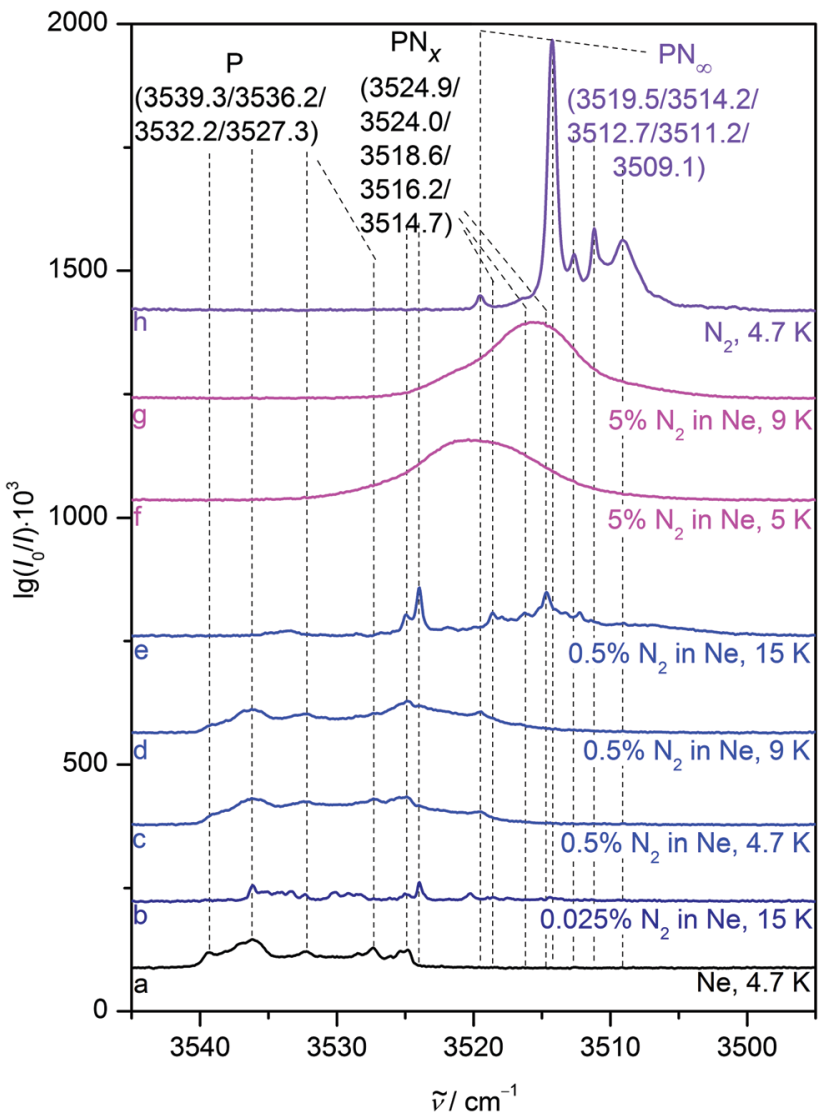

Fig. $6 \mathrm{NH}$ stretching FTIR spectra of $0.025 \%$ pyrrole in a neon matrix after deposition at $4.7 \mathrm{~K}$ (trace a). Spectra of neon matrices with increasing nitrogen addition (traces $\mathrm{b}$ to $\mathrm{g}$ ) before and after annealing to the stated temperature and subsequent recooling to $4.7 \mathrm{~K}$ as well as a nitrogen matrix deposited at $20 \mathrm{~K}$ and subsequently cooled to $4.7 \mathrm{~K}$ (trace h) are also included. Wavenumbers and (tentative) assignments are provided.

to a more dispersed distribution of nearly equivalent classes of oscillators.

Very similar behaviour is observed in argon matrices (Fig. 7), even though the band positions of $\mathrm{P}$ in pure argon are already closer to the $\mathrm{N}_{2}$ matrix bands than corresponding neon transitions. 


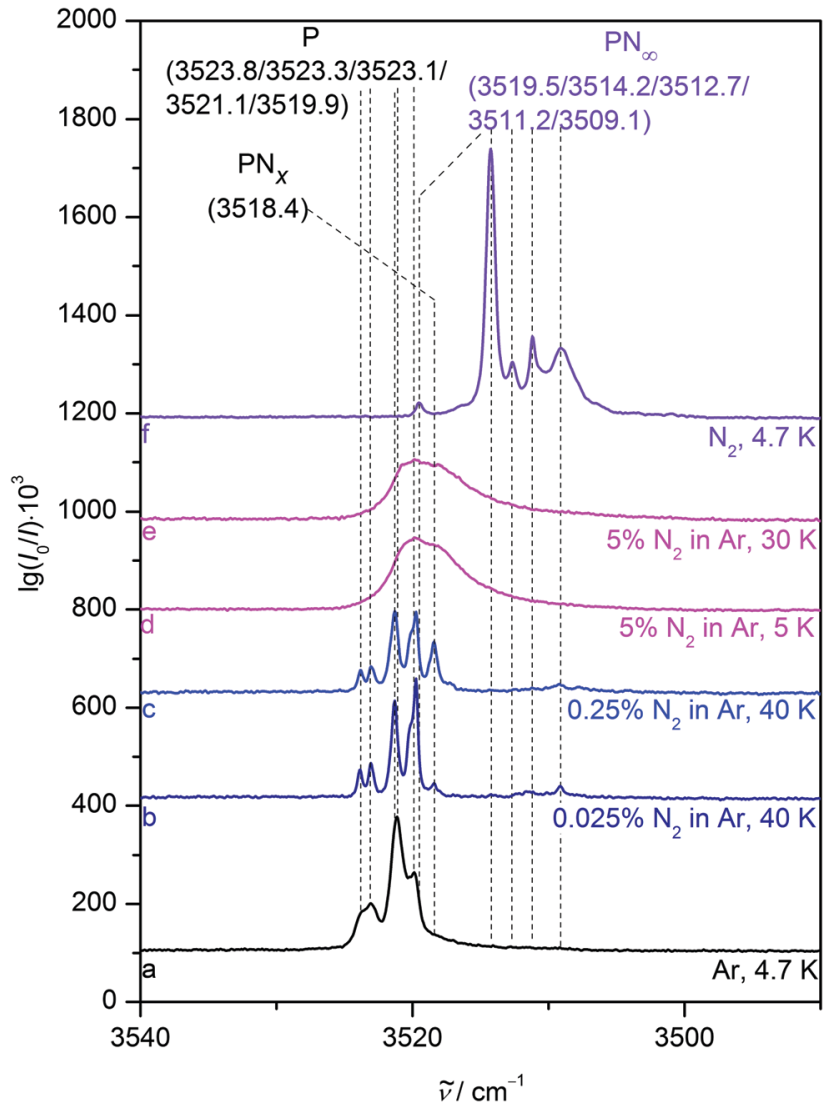

Fig. $7 \mathrm{NH}$ stretching FTIR spectra of $0.025 \%$ pyrrole in an argon matrix after deposition at $20 \mathrm{~K}$ and subsequent cooling to $4.7 \mathrm{~K}$ (trace a). Spectra of argon matrices with increasing nitrogen addition (traces $b$ to e) before and after annealing to the stated temperature and subsequent recooling to $4.7 \mathrm{~K}$ as well as a nitrogen matrix deposited at $20 \mathrm{~K}$ and cooled to $4.7 \mathrm{~K}$ (trace f) are also included. Wavenumbers and (tentative) assignments are provided.

Adding small amounts of 0.025 and $0.25 \% \mathrm{~N}_{2}$ to the argon matrix and annealing to $40 \mathrm{~K}$ (traces $\mathrm{b}$ and c) results in new features at 3518.4 and $3509.1 \mathrm{~cm}^{-1}$, most likely due to binary $\mathrm{PN}$ complexes. The larger $5 \%$ nitrogen fraction (traces $\mathrm{d}$ and $\mathrm{e}$ ) again results in a broad band that is downshifted towards the pure $\mathrm{N}_{2}$ matrix band position (trace $\mathrm{f}$ ). Interestingly, this approach to pure $\mathrm{N}_{2}$ is spectrally less complete for the argon host $\left(3520 \mathrm{~cm}^{-1}\right)$ than for the neon host, in particular after annealing $\left(3515 \mathrm{~cm}^{-1}\right)$. This probably reflects the softness of the neon matrix, which allows for a closer arrangement of the $\mathrm{N}_{2}$ dopant around $\mathrm{P}$, still sufficiently diluted by the matrix host to prevent sharp spectral features due to long range order. Indeed, neon is one of the softest matrices, exhibiting a crystal

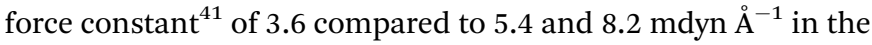
case of nitrogen and argon matrices, respectively.

\subsection{Supersonic Expansions}

Removing matrix-induced wavenumber shifts in a supersonic expansion (Fig. 8) yields the unperturbed $\mathrm{P}$ band position of $3531 \mathrm{~cm}^{-1}$ and a hot band $\left(\mathrm{P}_{\text {hot }}\right)$ at $3507 \mathrm{~cm}^{-1}$, in excellent agreement with previous studies. ${ }^{18,26,27}$ The hot transition

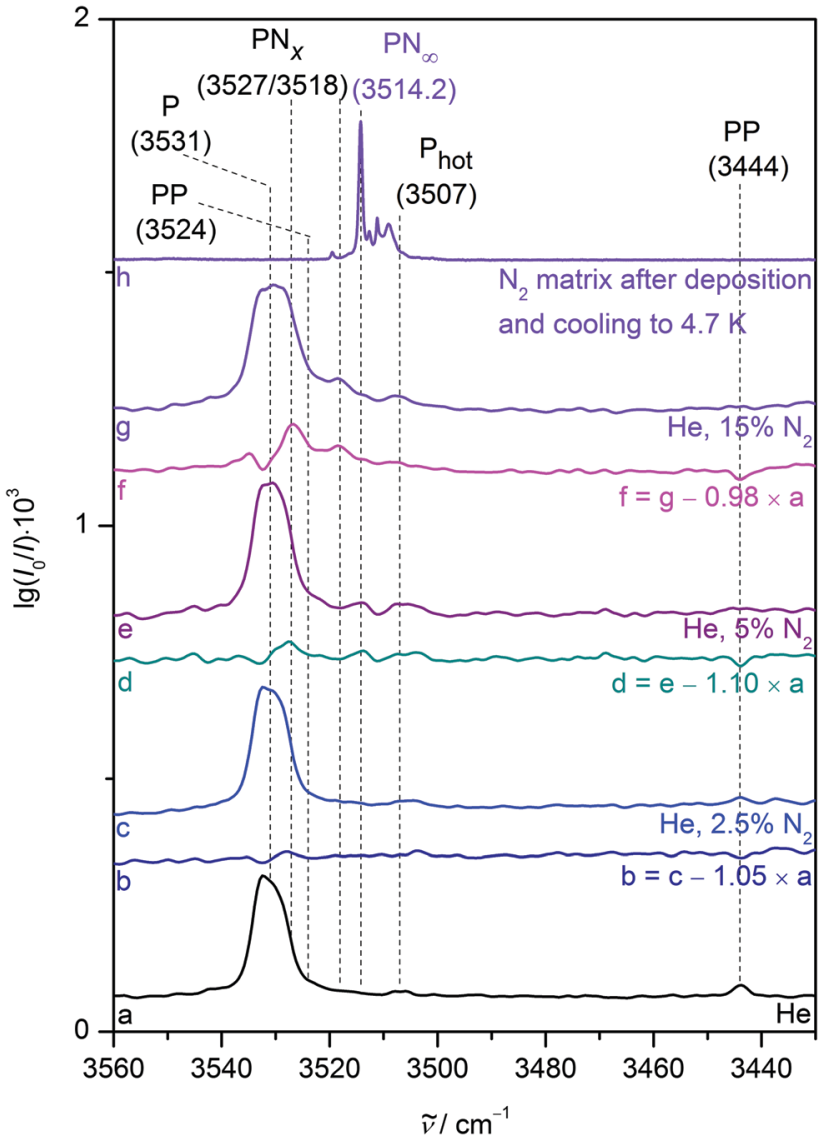

Fig. $8 \mathrm{NH}$ stretching FTIR jet spectra of about $0.1 \%$ pyrrole expanded in different mixtures of nitrogen and helium (traces $a, c$, e and g) as well as monomer-subtracting difference spectra (traces $b, d$ and f). Trace $h$ is taken from Fig. 5 (trace a) and divided by 2000. Wavenumbers and (tentative) assignments are provided.

occurs due to insufficient vibrational cooling of the thermally excited out-of-plane bending mode $\nu_{16}$ at $474.61 \mathrm{~cm}^{-1}$ in the helium jet expansion. ${ }^{27}$

Adding 2.5 and $5 \% \mathrm{~N}_{2}$ to the gas mixture (traces c and e) results in a new feature at $3527 \mathrm{~cm}^{-1}$, more clearly visible in the P-corrected difference spectra (traces $b$ and d). Similar expansion conditions resulted in the formation of singly or doubly nitrogen coordinated clusters of alcohols ${ }^{9,42}$ or carboxylic acids ${ }^{10}$ and the $5 \mathrm{~cm}^{-1}$ downshift from the isolated monomer is in reasonable agreement with the nitrogeninduced shifts in neon and argon matrices as well as harmonic predictions for various small $\mathrm{NH}$-coordinated PN clusters. If $15 \%$ nitrogen is added to the helium carrier gas (traces $\mathrm{f}$ and $\mathrm{g}$ ), a band at $3518 \mathrm{~cm}^{-1}$ emerges. The close proximity to the $\mathrm{N}_{2}$ matrix band position suggests nitrogen nanocoating of $\mathrm{P}$ in the expansion, analogous to effects observed for alcohol dimers under similar expansion conditions. ${ }^{9}$ It would be desirable to quantify the spectral effects of stepwise $\mathrm{N}_{2}$ coating of pyrrole using size-selective and/or high resolution ro-vibrational spectroscopy, but for the time being, the qualitative trends are unambiguous in terms of the direction of the wavenumber shift. 


\section{Conclusions}

Stepwise nitrogen complexation of the pyrrole monomer in neon and argon matrices as well as supersonic expansions nicely bridges the gap between isolated gas phase and bulk nitrogen matrix environments (Fig. 9). The total gas-to-matrix downshift of the $\mathrm{NH}$ stretching vibration is incrementally reproduced, initially by coordination of a few nitrogen molecules at the NH proton. Density functional theory within the double harmonic approximation is able to describe this effect with reasonable accuracy. The final bulk matrix NH stretching band position is approached by embedding of pyrrole in larger amounts of nitrogen both in cryogenic matrices and the gas phase. Standard harmonic calculations for larger pyrrole nitrogen clusters clearly fail to accurately describe the bulk limit but it remains unclear whether this is due to their finite size and amorphous character or due to an electronic structure or anharmonicity deficiency. The $-16.6 \mathrm{~cm}^{-1}$ bulk $\mathrm{N}_{2}$ wavenumber

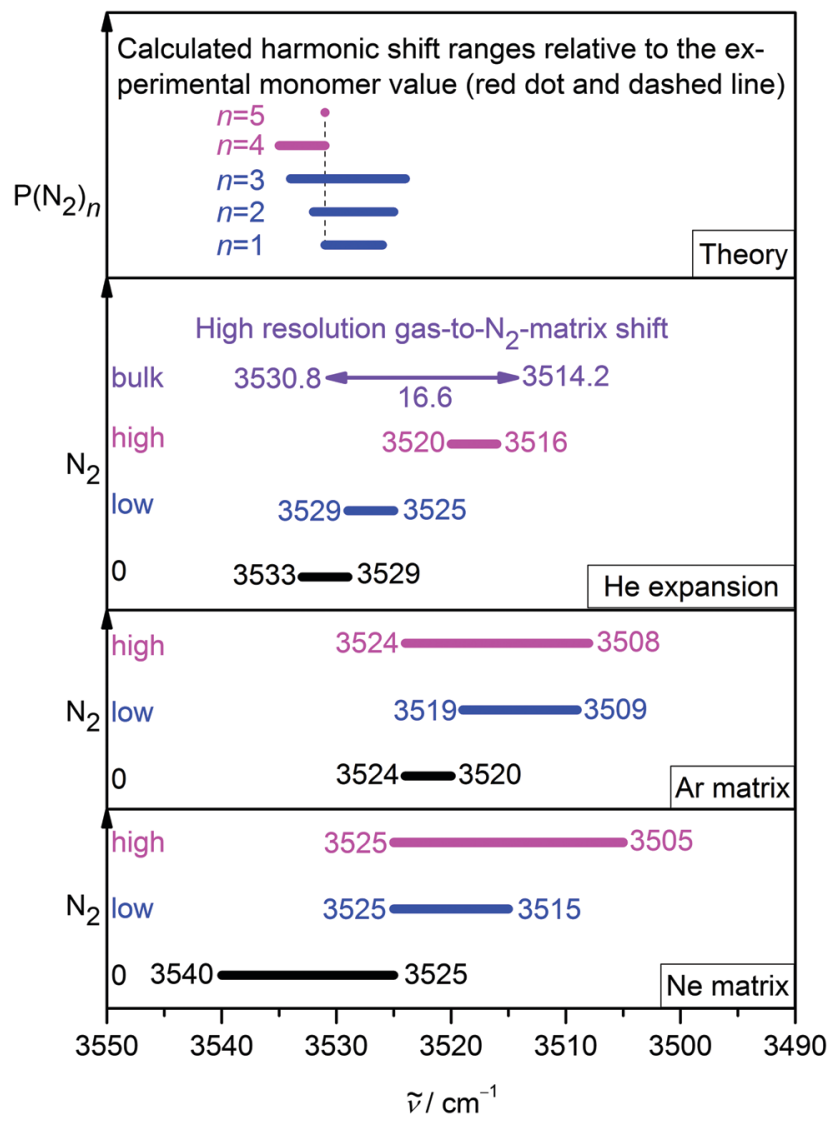

Fig. $9 \mathrm{NH}$ stretching band positions of the pyrrole monomer in neon and argon cryomatrices as well as in supersonic helium expansions. Increasing nitrogen admixture causes progressive downshifts of the band position in all three environments, approaching the bulk $\mathrm{N}_{2}$ matrix limit. High resolution gas phase $^{26}$ and nitrogen matrix spectra allow for an accurate determination of the total gas-to-matrix downshift to $16.6 \mathrm{~cm}^{-1}$. The range of wavenumber shifts predicted for the most stable pyrrole-nitrogen complexes by harmonic B3LYP-D3(BJ)/aVTZ calculations nicely reproduces experimental findings with reasonable accuracy for the first three added nitrogen molecules, but the tested approach fails to describe continuous downshifts in more nitrogenenriched environments and the bulk limit. shift represents a challenging experimental benchmark which promises to provide deep insights into weak hydrogen bond and packing effects, if addressed properly by theory. ${ }^{43}$ We anticipate that this may even be possible to a satisfactory degree in the harmonic oscillator approximation, if a possible "forced contact" nature of the $\mathrm{NH} \cdots \mathrm{N}_{2}$ interaction in the bulk matrix is considered. For this, accurate pair potentials of dinitrogen ${ }^{44}$ have to be combined with interaction potentials for pyrrole- $\mathrm{N}_{2}$, perhaps in the form of neural networks. ${ }^{45}$ This might confirm on a quantitative level what the present contribution shows qualitatively, based on multiple experimental evidence: significant upshifting of the $\mathrm{NH}$ stretching fundamental induced by $\mathrm{N}_{2}$ is neither an issue in the matrix nor in the gas phase.

\section{Conflicts of interest}

There are no conflicts to declare.

\section{Acknowledgements}

S. Oswald thanks the FCI for a generous scholarship.

\section{References}

1 E. Whittle, D. A. Dows and G. C. Pimentel, J. Chem. Phys, 1954, 22, 1943-1944.

2 K. Yoshioka, P. L. Raston and D. T. Anderson, Int. Rev. Phys. Chem., 2006, 25, 469-496.

3 C. Pirim and L. Krim, Phys. Chem. Chem. Phys., 2011, 13, 19454-19459.

4 A. D. Buckingham, R. L. Disch and D. A. Dunmur, J. Am. Chem. Soc., 1968, 90, 3104-3107.

5 S. Coussan, Y. Bouteiller, J. P. Perchard and W. Q. Zheng, J. Phys. Chem. A, 1998, 102, 5789-5793.

6 G. L. D. Ritchie, J. N. Watson and R. I. Keir, Chem. Phys. Lett., 2003, 370, 376-380.

7 A. Gómez-Zavaglia and R. Fausto, J. Phys. Chem. A, 2004, 108, 6953-6967.

8 J. J. Lee, S. Höfener, W. Klopper, T. N. Wassermann and M. A. Suhm, J. Phys. Chem. C, 2009, 113, 10929-10938.

9 S. Oswald, M. Wallrabe and M. A. Suhm, J. Phys. Chem. A, 2017, 121, 3411-3422.

10 S. Oswald, E. Meyer and M. A. Suhm, J. Phys. Chem. A, 2018, 122, 2933-2946.

11 R. Kanakaraju and P. Kolandaivel, Int. J. Mol. Sci., 2002, 3, 777-789.

12 L. Fredin, B. Nelander and G. Ribbegård, J. Mol. Spectrosc., 1974, 53, 410-416.

13 L. Andrews and S. R. Davis, J. Chem. Phys., 1985, 83, 4983-4989. 14 J. Sadlej, B. Rowland, J. P. Devlin and V. Buch, J. Chem. Phys., 1995, 102, 4804-4818.

15 C. Douketis and J. P. Reilly, J. Chem. Phys., 1992, 96, 3431-3440. 16 U. Nygaard, J. Nielsen, J. Kirchheiner, G. Maltesen, J. RastrupAndersen and G. O. Sørensen, J. Mol. Struct., 1969, 3, 491-506. 17 G. Columberg and A. Bauder, J. Chem. Phys., 1997, 106, 504-510. 
18 Y. Matsumoto and K. Honma, J. Chem. Phys., 2007, 127, 184310. 19 M. Schütz, Y. Matsumoto, A. Bouchet, M. Öztürk and O. Dopfer, Phys. Chem. Chem. Phys., 2017, 19, 3970-3986.

20 S. Kumar and A. Das, J. Chem. Phys., 2012, 136, 174302.

21 V. Profant, V. Poterya, M. Fárník, P. Slavícek and U. Buck, J. Phys. Chem. A, 2007, 111, 12477-12486.

22 S. Sarkar, N. Ramanathan, R. Gopi and K. Sundararajan, J. Mol. Struct., 2017, 1149, 387-403.

23 P. Pandey, RSC Adv., 2015, 5, 79661-79664.

24 M.-C. Bernard-Houplain and C. Sandorfy, Can. J. Chem., 1973, 51, 1075-1082.

25 V. Stefov, L. Pejov and B. Šoptrajanov, J. Mol. Struct., 2003, 649, 231-243.

26 A. Mellouki, R. Georges, M. Herman, D. L. Snavely and S. Leytner, Chem. Phys., 1997, 220, 311-322.

27 I. Dauster, C. A. Rice, P. Zielke and M. A. Suhm, Phys. Chem. Chem. Phys., 2008, 10, 2827-2835.

28 K. B. Moore, K. Sadeghian, C. D. Sherrill, C. Ochsenfeld and H. F. Schaefer, J. Chem. Theory Comput., 2017, 13, 5379-5395.

29 S. A. McDowell, Chem. Phys. Lett., 2017, 674, 146-150.

30 D. L. Jadhav, N. K. Karthick, P. P. Kannan, R. Shanmugam, A. Elangovan and G. Arivazhagan, J. Mol. Struct., 2017, 1130, 497-502.

31 A. Trivella, T. N. Wassermann, C. Manca Tanner, N. O. B. Lüttschwager and S. Coussan, J. Phys. Chem. A, 2018, 122, 2376-2393.

32 T. N. Wassermann, D. Luckhaus, S. Coussan and M. A. Suhm, Phys. Chem. Chem. Phys., 2006, 8, 2344-2348.

33 A. Trivella, T. N. Wassermann, J. M. Mestdagh, C. Manca Tanner, F. Marinelli, P. Roubin and S. Coussan, Phys. Chem. Chem. Phys., 2010, 12, 8300-8310.

34 T. N. Wassermann, M. A. Suhm, P. Roubin and S. Coussan, J. Mol. Struct., 2012, 1025, 20-32.

35 M. A. Suhm and F. Kollipost, Phys. Chem. Chem. Phys., 2013, 15, 10702-10721.
36 M. J. Frisch, G. W. Trucks, H. B. Schlegel, G. E. Scuseria, M. A. Robb, J. R. Cheeseman, G. Scalmani, V. Barone, B. Mennucci, G. A. Petersson, H. Nakatsuji, M. Caricato, X. Li, H. P. Hratchian, A. F. Izmaylov, J. Bloino, G. Zheng, J. L. Sonnenberg, M. Hada, M. Ehara, K. Toyota, R. Fukuda, J. Hasegawa, M. Ishida, T. Nakajima, Y. Honda, O. Kitao, H. Nakai, T. Vreven, J. A. Montgomery, J. E. Peralta, F. Ogliaro, M. Bearpark, J. J. Heyd, E. Brothers, K. N. Kudin, V. N. Staroverov, R. Kobayashi, J. Normand, K. Raghavachari, A. Rendell, J. C. Burant, S. S. Iyengar, J. Tomasi, M. Cossi, N. Rega, J. M. Millam, M. Klene, J. E. Knox, J. B. Cross, V. Bakken, C. Adamo, J. Jaramillo, R. Gomperts, R. E. Stratmann, O. Yazyev, A. J. Austin, R. Cammi, C. Pomelli, J. W. Ochterski, R. L. Martin, K. Morokuma, V. G. Zakrzewski, G. A. Voth, P. Salvador, J. J. Dannenberg, S. Dapprich, A. D. Daniels, O. Farkas, J. B. Foresman, J. V. Ortiz, J. Cioslowski and D. J. Fox, Gaussian 09 Revision E.01, Gaussian Inc., Wallingford CT, 2009.

37 J. Bloino and V. Barone, J. Chem. Phys., 2012, 136, 124108.

38 C. Pfaffen, D. Infanger, P. Ottiger, H.-M. Frey and S. Leutwyler, Phys. Chem. Chem. Phys., 2011, 13, 14110-14118.

39 R. Knochenmuss, R. K. Sinha and S. Leutwyler, J. Chem. Phys., 2018, 148, 134302.

40 R. K. Bohn, K. W. Hillig and R. L. Kuczkowski, J. Phys. Chem., 1989, 93, 3456-3459.

41 L. Andrews and M. Moskovits, Chemistry and Physics of Matrix-Isolated Species, North-Holland, Amsterdam, 1989.

42 S. Oswald and M. A. Suhm, Angew. Chem., Int. Ed., 2017, 56, 12672-12676.

43 R. A. Mata and M. A. Suhm, Angew. Chem., Int. Ed., 2017, 56, 11011-11018.

44 A. van der Avoird, P. E. S. Wormer and A. P. J. Jansen, J. Chem. Phys., 1986, 84, 1629-1635.

45 J. Behler, Int. J. Quantum Chem., 2015, 115, 1032-1050. 